\title{
Descentralização do Programa Bolsa Família: determinantes do desempenho municipal
}

Pedro Luiz Cavalcante Beatriz Bernardes Ribeiro 


\section{Resumo}

O ARTIGO OBJETIVA TESTAR OS POSSÍVEIS DETERMINANTES DO DESEMPENHO MUNICIPAL NO BRASIL. PARA TANTO, UTILIZA-SE A EXECUÇÃO descentralizada do Programa Bolsa Família (PBF), uma VeZ oue APRESENTA SIGNIFICATIVA VARIABILIDADE. PRESSUPÕE OUE O GESTOR LOCAL É MOTIVADO E CONSTRANGIDO POR FATORES ESTRUTURAIS, BEM COMO PELAS REGRAS DO JOGO POLÍTICO E RESULTADOS ELEITORAIS. O TRABALHO FUNDAMENTA-SE EM UM MODELO ESTATÍSTICO DE REGRESSÃO MÚLTIPLA OUUE INCLUI A TOTALIDADE DOS MUNICÍPIOS BRASILEIROS. CONCLUI-SE QUE A ESTRATÉGIA DE DESCENTRALIZAÇÃO FOI BEM-SUCEDIDA AO ATINGIR TODAS AS PREFEITURAS E CRIAR INCENTIVOS PARA DESEMPENHEM SATISFATORIAMENTE AS ATIVIDADES DO PBF, INDEPENDENTEMENTE DA POSIÇÃO GEOGRÁFICA OU SITUAÇÃO ECONÔMICA. NO ENTANTO, OS RESULTADOS DA MAIORIA DAS VARIÁVEIS POLÍTICAS MINIMIZAM A RELEVÂNCIA DESSA DIMENSÃO NA ANÁLISE DAS POLÍTICAS SOCIAIS NO PAÍS.

\section{Abstract}

THE ARTICLE AIMS TO TEST POSSIBLE DETERMINANTS OF MUNICIPAL PERFORMANCE IN BRAZIL. IN THIS SENSE, the DeCEntralized IMPlementation of the PrograMA BOLSA FAMÍLIA IS USED, CONSIDERING ITS SIGNIFICANT VARIABILITY. THE THEORETICAL ASSUMPTION IS THAT THE MAYOR IS MOTIVATED AND CONSTRAINED BY STRUCTURAL FACTORS, AS WELL AS BY THE RULES OF THE POLITICAL GAME AND ELECTION RESULTS. THE INQUIRY IS BASED ON A STATISTICAL MODEL OF MULTIPLE REGRESSION THAT INCLUDES ALL THE MUNICIPALITIES. WE CONCLUDE THAT THE DECENTRALIZATION WAS SUCCESSFUL IN REACHING ALL MUNICIPALITIES AND CREATING INCENTIVES FOR REASONABLE PERFORMANCE, REGARDLESS OF GEOGRAPHIC LOCATION OR ECONOMIC CONDITION. HOWEVER, MOST OF THE POLITICAL VARIABLES RESULTS HELP TO MINIMIZE THIS DIMENSION RELEVANCE IN THE ANALYSIS OF BRAZILIAN SOCIAL POLICIES.

\section{PALAVRAS-CHAVE:}

Federalismo; Governo Municipal; Descentralização de Políticas Sociais; Eleições.

Revista Brasileira de Monitoramento e Avaliação | Número 3 | Janeiro-Junho de 2012 


\section{Introdução}

O presente trabalho visa desenvolver um estudo empírico acerca dos fatores que determinam a qualidade da gestão municipal das políticas públicas no Brasil. Para tanto, o artigo utiliza a gestão descentralizada do Programa Bolsa Família (PBF) como forma de testar os possíveis determinantes do desempenho local.

O argumento central da literatura de descentralização de políticas públicas é que o requisito para o sucesso de uma política descentralizada é a criação de arranjo institucional que incentive a cooperação intergovernamental. Como veremos a seguir, no PBF, o governo federal implantou essa estratégia de indução à participação pautada no apoio técnico e financeiro aos governos subnacionais, mediante o Índice de Gestão Descentralizada (IGD). Passados alguns anos, nota-se que tal iniciativa teve impacto positivo sobre a gestão local do programa, porém ela não explica a disparidade entre o desempenho dos municípios brasileiros.

Dessa forma, a pesquisa objetiva contribuir não apenas ao debate acadêmico dessa linha de pesquisa, mas também fornecer subsídios metodologicamente válidos aos tomadores de decisões de modo a entenderem melhor os fatores e dinâmicas subjacentes que obstruem ou favorecem a consolidação da gestão compartilhada nas políticas sociais do País.

O artigo inicia com um breve debate sobre descentralização de políticas públicas no Brasil. Em seguida, o processo de implementação do PBF é descrito ressaltando a questão da variação do desempenho municipal no que tange à execução das atividades do programa. Ademais, são expostas a metodologia e as variáveis do modelo da pesquisa. Finalmente, os seus resultados e considerações finais são discutidos.

\section{Descentralização no Brasil}

Devido a sua relevância e complexidade, o termo descentralização possui uma miríade de conceituações que, de modo geral, consiste na transferência de autoridade e responsabilidade em questões públicas do centro para a periferia. Não se trata de um fenômeno monolítico, pois a descentralização envolve uma multiplicidade de desenhos, formas e estágios de implementação e, principalmente, é modificada de acordo com as transformações políticas, econômicas e sociais. Atualmente, observa-se a convergência da literatura para uma perspectiva mais ampla de governança ou de governança descentralizada’

Quanto aos seus tipos, uma classificação difundida é a de Cheema e Rondinelli (1983), que dividem a descentralização em quatro formas ideais com base em seus objetivos². O foco dessa pesquisa é uma dessas formas: a devolução de funções e autoridade do governo central para as unidades autônomas locais com delimitação territorial legalmente reconhecida e que possuem poder e capacidade operacional.

A descentralização é vista tanto como um instrumento viável para a implantação da política como também uma forma de alcançar melhorias na eficiência alocativa e equidade, ao ampliar a participação comunitária e a trans- 
parência. Por outro lado, esses resultados não são uniformes entre os países, do mesmo modo que não são poucos os casos de fracassos na implementação da descentralização³.

Além disso, a proliferação de práticas descentralizadas evidencia que não se trata de uma panacéia para solucionar problemas de desenvolvimento, iniquidade ou falta de participação política, pois também podem culminar em efeitos perversos não apenas nos países emergentes mas também nos desenvolvidos ${ }^{4}$.

O tema ganha relevância no Brasil, uma vez que o País é muitas vezes considerado o mais descentralizado do mundo ${ }^{5}$, o que possui forte relação com a sua estrutura federativa particular. Os estudos sobre o tema ocupam boa parte da agenda de pesquisa, haja vista que a descentralização e o consequente compartilhamento de responsabilidades entre União, estados e municípios fundamentam a implementação dos principais programas governamentais no País.
De acordo com Arretche (2002), a descentralização no Brasil pode ser subdividida em dois momentos: um nos anos 80, com a retomada das eleições diretas e as deliberações da Constituição Federal de 1988, que recuperaram as bases federativas do Estado; o outro a partir da década seguinte, que constitui a implementação de uma ampla estratégia de descentralização administrativa, principalmente nas políticas sociais.

O arranjo federativo brasileiro é complexo e apresenta tendências simultâneas tanto centralizadoras quanto descentralizadoras, variando de acordo com os atores, arenas e interesses envolvidos ${ }^{6}$. Nesse contexto, a Constituição de 1988 é um marco, embora também apresente lacunas no que tange à operacionalização de ações de coordenação e cooperação entre esses atores. Além disso, a disparidade histórica entre as regiões e municípios brasileiros no tocante à capacidade financeira, aos recursos humanos e à estrutura física para gerir as políticas sociais também é considerada um obstáculo para a descentralização das políticas sociais no Brasil?.

1 (World Bank, 2010; Cheema e Rondinelli, 2007.)

2 Para detalhamento de cada uma dessas formas de descentralização ver Cheema e Rondinelli (1983, pp. 18-25).

3 (Bossert, 1996; Cheema e Rondinelli, 1983, 2007; Faguet, 1997.)

4 (Melo, 1996; World Bank, 2010.)

5 (Arretche, 2009; Abrúcio, 2005.)

6 (Arretche, 2000; Almeida, 2005; Abrúcio, 2006.)

7 (Almeida, 1996; Affonso; Silva, 1996.)

Revista Brasileira de Monitoramento e Avaliação | Número 3 | Janeiro-Junho de 2012 
Outras questões também demonstram convergências na literatura de descentralização no País: primeiro, a prioridade à municipalização dos serviços; segundo, o governo federal com papéis de coordenação e financiamento; e por fim, o sucesso das experiências vinculado à criação de uma estrutura de incentivos aos governos subnacionais.

A tendência de enfatizar os municípios como principais provedores de serviços públicos, e não os estados, é tanto uma inovação como uma consequência do federalismo brasileiro. A proximidade maior para obter informações sobre as preferências e necessidades da população local é considerada fator preponderante para a execução das políticas públicas via municípios.

Quanto ao governo federal, este tem sido o protagonista da coordenação federativa, em função da sua posição estratégica em relação aos governos subnacionais e do papel de financiador e normatizador ${ }^{8}$. Segundo Arretche (2009), os poderes regulatórios e de definição de gastos são bem concentrados no nível central, o que culmina no monitoramento dos governos subnacionais no que tange às finanças e à execução dos programas federais.

Finalmente, o terceiro aspecto de convergência é a percepção de que a viabilidade das iniciativas de descentralização no Brasil deve-se, principalmente, à construção de um arranjo institucional que reflita incentivos à participação efetiva, fluxo contínuo de informação, capacidade de controle e accountability. $\mathrm{E}$, consequentemente, resulte no federal e subnacionais`. Na mesma direção, o Banco Mundial defende que o sucesso da política depende da observância dos seguintes princípios no desenho da implementação: financiamento das funções; processo decisório bem informado; aderência a prioridades locais e accountability ${ }^{10}$. Em síntese, uma das facetas da descentralização envolve a institucionalização no plano local de condições técnicas para a efetiva execução de tarefas de gestão das políticas sociais. No entanto, não se trata de uma tarefa trivial.

No caso brasileiro, a investigação aprofundada da implementação de uma política social no Brasil requer a análise de aspectos relativos ao papel tanto do governo federal quanto dos subnacionais, em especial dos municípios. É crucial observar o desenho e o funcionamento da gestão compartilhada com foco nos efeitos das iniciativas de indução à cooperação e de outras variáveis sobre o comportamento desses atores.

\section{Bolsa Família e a Gestão Descentralizada}

$O \mathrm{PBF}^{11}$ é resultante de um processo de unificação dos procedimentos de gestão e execução das políticas de Transferência Condicionada de Renda (TCR) ${ }^{12}$ do governo federal ${ }^{13}$. Ele beneficia famílias em situação de pobreza e extrema pobreza e tem como objetivo oferecer proteção a todo grupo familiar e contribuir para seu desenvolvimento. Para tanto, fundamenta-se em três dimensões. Primeiro, a promoção do alívio imediato da pobreza por meio da transferência direta de renda. Segundo, o reforço ao exercício de direitos sociais básicos nas áreas de saúde, 
educação e assistência social por meio do cumprimento das condicionalidades. E, por fim, a integração com programas complementares, que visa auxiliar e capacitar as famílias de modo que os beneficiários consigam superar a situação de vulnerabilidade e pobreza ${ }^{14}$.

O programa constitui a maior política pública de TCR da América Latina, tanto em orçamento quanto em cobertura ${ }^{15}$. Atualmente, atende à totalidade da estimativa de famílias pobres do Brasil, ou seja, cerca 13,7 milhões de famílias em todos os municípios do país com dispêndio de mais de R\$ 24 bilhões por ano.
Após um curto período de existência, o Programa e seus rápidos resultados chamaram a atenção não apenas de instituições e autoridades do Brasil, mas também de organismos multilaterais, do meio acadêmico internacional e de governos de outros países dispostos a replicar o modelo.

Avaliações de impacto demonstram que o PBF contribui para a elevação da frequência escolar, a ampliação do atendimento à saúde e o combate à desnutrição ${ }^{16}$. O PBF e o Benefício de Prestação Continuada (BPC) ${ }^{17}$ têm impacto significativo na redução da pobreza e desigualdade. Além disso, não reduzem a

8 (Almeida, 1996; Affonso; Silva, 1996.)

9 (Bossert, 1996; Faguet, 1997; Arretche, 2000; Kaufman e Nelson, 2004; Nelson, 2004.)

10 (World Bank, 2010.)

11 Criado pela Medida Provisória n 132, de 20 de outubro de 2003, posteriormente convertida na Lei n 10.836 , de 9 de janeiro de 2004 .

12 Esse tipo de política pública possui uma diversidade de denominações. Para fins dessa pesquisa, optou-se pelo termo Transferência Condicionada de Renda (TCR), adotado pelo Centro Internacional de Políticas para o Crescimento Inclusivo (IPC-IG), antigo Centro Internacional de Pobreza. O IPC-IG é uma parceria entre o Grupo de Pobreza do Departamento de Políticas de Desenvolvimento, o Programa das Nações Unidas para o Desenvolvimento (PNUD) e o governo brasileiro.

13 Programa Nacional de Renda Mínima Vinculada à Educação (Bolsa Escola) - Lei nº 10.219/2001, Programa Nacional de Acesso à Alimentação (PNAA) - Lei no 10.689/2003, Programa Nacional de Renda Mínima Vinculada à Saúde (Bolsa Alimentação) - Medida Provisória n 2.206-1/2001, Programa Auxílio-Gás - Decreto n 4.102/2002 e Cadastro Único para Programas Sociais do Governo Federal - Decreto nº 6.135/2007.

14 (Cohn e Fonseca, 2004.)

15 (MDS, 2008.)

16 (Soares, Ribas e Osório, 2007; MDS, 2007a.)

17 O Benefício de Prestação Continuada (BPC) é um direito garantido pela Constituição Federal de 1988 que consiste no pagamento de um salário mínimo mensal a pessoas com 65 anos de idade ou mais e a pessoas com deficiência incapacitante para a vida independente e para o trabalho.

Revista Brasileira de Monitoramento e Avaliação | Número 3 | Janeiro-Junho de 2012 
predisposição ao trabalho nem a contribuição previdenciária, como é rotineiramente argumentado pelos críticos $^{18}$.

De acordo com Lindert et al (2007), a atração pelo PBF deve-se a uma série de motivos, dentre eles: eficiente experiência de unificação dos programas de TCR; magnitude e rápida expansão, o que o torna o maior programa desse tipo no mundo; impressionante precisão da focalização; impactos positivos comprovados na redução da pobreza e da desigualdade; papel do PBF na integração de políticas sociais, tanto de forma horizontal entre setores como verticalmente em níveis de governos. Delgado, Jaccoud e Nogueira (2008) argumentam que o PBF representa uma evolução nessa modalidade de política pública à medida que amplia o sistema de garantia de renda da proteção social brasileira, atingindo segmentos populacionais historicamente nunca atendidos pela assistência social.

Embora a concepção inovadora ${ }^{19}$ do PBF tenha influência nos resultados supracitados, boa parte é creditada à estratégia de descentralização do programa ${ }^{20}$. Nesse sentido, as ações de cooperação e coordenação intergovernamental são fundamentais à medida que o governo federal isolado não dispõe de capacidade operacional para implementar as atividades de identificação e cadastramento das famílias pobres, acompanhamento das condicionalidades, gestão dos benefícios e fiscalização. A eficácia dessas ações pressupõe a concretização da ação compartilhada entre os entes federados.

Diante desses desafios, no momento da formulação do PBF foram inseridos no desenho normativo e na sua estrutura administrativa ${ }^{21}$ princípios que apontavam para o estabelecimento de parcerias com diferentes áreas do governo, estados, setores da sociedade civil e, especialmente, os municípios ${ }^{22}$.

Nos primeiros anos do PBF, entretanto, o governo federal detectou que a incorporação de dispositivo formal não implicou necessariamente a efetiva execução do programa por parte dos entes. As dificuldades da gestão compartilhada eram oriundas de alguns fatores. Primeiro, a indefinição quanto às responsabilidades e competências de cada ente e a ausência de mecanismos claros e efetivos de coordenação e cooperação.

Segundo, a forte identificação do programa com o governo federal ${ }^{23}$ não gerava o interesse nos políticos municipais em investir em suas atividades em decorrência da pequena perspectiva de reconhecimento e ganhos políticos. Em outras palavras, o diagnóstico indicava que o PBF gerava custos adicionais ao mesmo tempo em que não trazia benefícios imediatos aos prefeitos.

Como agravante, muitas administrações locais não possuem quadro de pessoal, tanto em termos quantitativos quanto qualitativos para lidar com essas tarefas. Isso fica evidente observando a Tabela 1 a seguir, onde é apresentada a distribuição da quantidade de servidores nas prefeituras dos municípios, por níveis de instrução e região. A partir desses dados, constatou-se que existem aproximadamente $2,5 \%$ da população que trabalha na administração direta dos municípios, mas que apenas 0,74\% tem nível superior, menor em contraposição a 0,76\% de pessoas sem instrução, quando somadas às do ensino fundamental e 1\% com ensino médio. 


\section{TABELA 1: DISTRIBUIÇÃO DE FUNCIONÁRIOS DAS PREFEITURAS POR REGIÃO E NÍVEIS DE INSTRUÇÃO}

\begin{tabular}{|c|c|c|c|c|c|c|c|c|c|c|}
\hline VARIÁVEL & & & & & REGI & & & & & \\
\hline & $\mathrm{N}$ & (\%) & NE & (\%) & $\mathrm{CO}$ & (\%) & SE & (\%) & $S$ & (\%) \\
\hline $\begin{array}{l}\text { Sem } \\
\text { Instrução }\end{array}$ & 12.653 & $3,02 \%$ & 58.434 & $3,94 \%$ & 6.292 & $2,26 \%$ & 40.186 & $2,28 \%$ & 9.432 & $1,42 \%$ \\
\hline $\begin{array}{l}\text { Ensino } \\
\text { Fundamental }\end{array}$ & 127.939 & $30,58 \%$ & 386.882 & $26,10 \%$ & 77.291 & $27,80 \%$ & 490.281 & $27,84 \%$ & 165.891 & $24,98 \%$ \\
\hline $\begin{array}{l}\text { Ensino } \\
\text { Médio }\end{array}$ & 195.425 & $46,70 \%$ & 687.107 & $46,36 \%$ & 105.667 & $38,00 \%$ & 645.078 & $36,63 \%$ & 252.232 & $37,99 \%$ \\
\hline $\begin{array}{l}\text { Ensino } \\
\text { Superior }\end{array}$ & 74.030 & $17,69 \%$ & 300.955 & $20,30 \%$ & 68.611 & $24,67 \%$ & 529.661 & $30,07 \%$ & 168.429 & $25,37 \%$ \\
\hline $\begin{array}{l}\text { Pós- } \\
\text { Graduação }\end{array}$ & 8.391 & $2,01 \%$ & 48.813 & $3,29 \%$ & 20.208 & $7,27 \%$ & 56.017 & $3,18 \%$ & 68.017 & $10,24 \%$ \\
\hline
\end{tabular}

Fonte: MUNIC/IBGE 2008 - Elaboração própria.

Apesar de a distribuição por estado da federação apresentar-se semelhante para os diversos níveis de instrução, ao se observar a Tabela 2 a seguir, pode-se perceber que os níveis mais baixos de instrução, observados nas re- giões Norte e Nordeste tendem a diminuir se comparados com os das regiões Sul e Sudeste. E no sentido contrário, os níveis mais altos de instrução tendem a aumentar das regiões Norte e Nordeste para as regiões Sul e Sudeste.

18 (Soares et al, 2007; Soares, Ribas e Osório, 2007; MDS, 2007a; Medeiros, Britto e Soares, 2008.)

19 Mais especificamente, as inovações em relação aos programas de TCR anteriores são: o atendimento a todo o grupo familiar independentemente da sua composição, o aumento substancial do valor do benefício em comparação aos programas anteriores, a universalização do público-alvo e a unificação das ações de TCR.

20 (Lindert et al, 2007; Medeiros, Britto e Soares, 2008.)

21 Embora tenha sido formulado a partir da articulação intersetorial entre ministérios da área social e econômica, sob a coordenação da Casa Civil e da assessoria da Presidência da República, após um breve período na Presidência, a gestão do programa foi transferida para o Ministério do Desenvolvimento Social e Combate à Fome (MDS). Nessa pasta, a Secretaria Nacional de Renda de Cidadania (Senarc) é a responsável pela coordenação, gestão e operacionalização do programa.

22 O Art. 11 do Decreto n 5.209, de 17 de setembro de 2004, estabelece que a implementação e gestão do PBF fundamentar-se-ão na descentralização, por meio da conjugação de esforços entre os entes federados, observada a intersetorialidade, a participação comunitária e o controle social.

23 (Licio, Rennó e Castro, 2009.)

Revista Brasileira de Monitoramento e Avaliação | Número 3 | Janeiro-Junho de 2012 
TABELA 2: DISTRIBUIÇÃO DE FUNCIONÁRIOS DAS PREFEITURAS POR REGIÃO, ESTADO E NÍVEIS DE INSTRUÇÃO

\begin{tabular}{|c|c|c|c|c|c|c|c|c|c|c|c|c|}
\hline $\begin{array}{l}\text { RE- } \\
\text { GIÃOO }\end{array}$ & UF & $\begin{array}{l}\text { MUNICÍ- } \\
\text { PIOS }\end{array}$ & $\begin{array}{c}\text { SEM } \\
\text { INSTRU- } \\
\text { ÇÃO }\end{array}$ & $(\%)$ & $\begin{array}{l}\text { ENSINO } \\
\text { FUNDA- } \\
\text { MENTAL }\end{array}$ & $(\%)$ & $\begin{array}{l}\text { ENSINO } \\
\text { MÉDIO }\end{array}$ & $(\%)$ & $\begin{array}{l}\text { ENSINO } \\
\text { SUPE- } \\
\text { RIOR }\end{array}$ & (\%) & $\begin{array}{c}\text { PÓS- } \\
\text { GRADUA- } \\
\text { ÇÃO }\end{array}$ & $(\%)$ \\
\hline \multirow{7}{*}{ NO } & $A C$ & 22 & 575 & $1,84 \%$ & 4.336 & $13,84 \%$ & 7.264 & $23,18 \%$ & 2.952 & $9,42 \%$ & 539 & $1,72 \%$ \\
\hline & AM & 62 & 1.480 & $0,84 \%$ & 23.367 & $13,26 \%$ & 41.979 & $23,83 \%$ & 16.479 & $9,35 \%$ & 1.597 & $0,91 \%$ \\
\hline & AP & 16 & 502 & $1,47 \%$ & 6.116 & $17,94 \%$ & 7.763 & $22,77 \%$ & 2.144 & $6,29 \%$ & 110 & $0,32 \%$ \\
\hline & PA & 143 & 7.247 & $1,78 \%$ & 62.145 & $15,26 \%$ & 90.888 & $22,32 \%$ & 31.510 & $7,74 \%$ & 2.320 & $0,57 \%$ \\
\hline & RO & 52 & 1.777 & $2,03 \%$ & 14.458 & $16,50 \%$ & 17.339 & $19,78 \%$ & 7.948 & $9,07 \%$ & 2.300 & $2,62 \%$ \\
\hline & RR & 15 & 135 & $0,50 \%$ & 3.973 & $14,79 \%$ & 6.958 & $25,90 \%$ & 2.051 & $7,63 \%$ & 318 & $1,18 \%$ \\
\hline & TO & 139 & 937 & $0,93 \%$ & 13.544 & $13,42 \%$ & 23.234 & $23,03 \%$ & 10.946 & $10,85 \%$ & 1.207 & $1,20 \%$ \\
\hline \multirow{9}{*}{ NE } & $A L$ & 98 & 6.665 & $3,64 \%$ & 21.968 & $11,99 \%$ & 37.185 & $20,30 \%$ & 18.109 & $9,89 \%$ & 2.484 & $1,36 \%$ \\
\hline & BA & 417 & 10.160 & $1,27 \%$ & 99.071 & $12,43 \%$ & 206.989 & $25,96 \%$ & 47.146 & $5,91 \%$ & 5.196 & $0,65 \%$ \\
\hline & CE & 184 & 9.530 & $1,92 \%$ & 58.533 & $11,81 \%$ & 97.088 & $19,60 \%$ & 58.993 & $11,91 \%$ & 10.373 & $2,09 \%$ \\
\hline & MA & 217 & 7.950 & $1,81 \%$ & 55.400 & $12,63 \%$ & 110.576 & $25,22 \%$ & 37.902 & $8,64 \%$ & 5.819 & $1,33 \%$ \\
\hline & PB & 223 & 7.033 & $2,56 \%$ & 39.246 & $14,28 \%$ & 53.063 & $19,30 \%$ & 32.090 & $11,67 \%$ & 6.020 & $2,19 \%$ \\
\hline & PE & 184 & 8.567 & $1,93 \%$ & 47.917 & $10,82 \%$ & 81.738 & $18,46 \%$ & 45.805 & $10,35 \%$ & 10.508 & $2,37 \%$ \\
\hline & $\mathrm{PI}$ & 223 & 3.207 & $1,77 \%$ & 23.430 & $12,97 \%$ & 36.935 & $20,44 \%$ & 21.211 & $11,74 \%$ & 3.815 & $2,11 \%$ \\
\hline & RN & 166 & 3.159 & $1,59 \%$ & 23.168 & $11,63 \%$ & 39.380 & $19,77 \%$ & 25.920 & $13,01 \%$ & 2.734 & $1,37 \%$ \\
\hline & SE & 75 & 2.163 & $1,73 \%$ & 18.149 & $14,54 \%$ & 24.153 & $19,35 \%$ & 13.779 & $11,04 \%$ & 1.864 & $1,49 \%$ \\
\hline \multirow{3}{*}{$\mathrm{CO}$} & GO & 246 & 2.887 & $0,96 \%$ & 38.592 & $12,85 \%$ & 50.444 & $16,79 \%$ & 27.684 & $9,22 \%$ & 5.053 & $1,68 \%$ \\
\hline & MS & 78 & 1.024 & $0,71 \%$ & 19.619 & $13,56 \%$ & 22.061 & $15,25 \%$ & 21.850 & $15,10 \%$ & 7.797 & $5,39 \%$ \\
\hline & MT & 139 & 2.381 & $1,43 \%$ & 19.080 & $11,47 \%$ & 33.162 & $19,93 \%$ & 19.077 & $11,47 \%$ & 7.358 & $4,42 \%$ \\
\hline \multirow{4}{*}{ SE } & ES & 78 & 2.393 & $1,09 \%$ & 26.906 & $12,29 \%$ & 41.209 & $18,83 \%$ & 26.781 & $12,23 \%$ & 8.840 & $4,04 \%$ \\
\hline & MG & 852 & 19.749 & $1,78 \%$ & 162.548 & $14,63 \%$ & 200.547 & $18,05 \%$ & 134.626 & $12,12 \%$ & 26.591 & $2,39 \%$ \\
\hline & RJ & 90 & 5.250 & $0,86 \%$ & 77.701 & $12,78 \%$ & 113.418 & $18,66 \%$ & 101.703 & $16,73 \%$ & 4.604 & $0,76 \%$ \\
\hline & SP & 642 & 12.794 & $0,78 \%$ & 223.126 & $13,68 \%$ & 289.904 & $17,78 \%$ & 266.551 & $16,34 \%$ & 15.982 & $0,98 \%$ \\
\hline \multirow{3}{*}{ SU } & $P R$ & 398 & 4.596 & $0,88 \%$ & 62.006 & $11,94 \%$ & 103.318 & $19,89 \%$ & 58.638 & $11,29 \%$ & 30.446 & $5,86 \%$ \\
\hline & RS & 494 & 2.121 & $0,44 \%$ & 63.630 & $13,12 \%$ & 89.678 & $18,49 \%$ & 65.402 & $13,49 \%$ & 19.235 & $3,97 \%$ \\
\hline & SC & 292 & 2.715 & $0,82 \%$ & 40.255 & $12,16 \%$ & 59.236 & $17,90 \%$ & 44.389 & $13,41 \%$ & 18.336 & $5.54 \%$ \\
\hline
\end{tabular}

Fonte: MUNIC/IBGE 2008 - Elaboração própria. 
Diante dessa realidade, a implementação do PBF demandava, assim, o fortalecimento de parcerias com base na definição clara de competências compartilhadas e de um processo de negociação de caráter de jogo de soma positiva, isto é, o ganho de um ator não necessariamente resulta na perda de outro. Ademais, o fato de o PBF ter sido criado por meio de legislação infraconstitucional, e não como um direito constitucional, tornou necessário implementar processos de negociação e coordenação federativa com características bastante diversas daquelas que são usuais nas políticas públicas brasileiras ${ }^{24}$.

Por conseguinte, a estratégia de gestão compartilhada do PBF foi formulada a partir de duas modalidades. A primeira, denominada de pactuação, consiste na formalização de parcerias com iniciativas de TCR dos governos subnacionais. A segunda corresponde à adesão formal dos entes ao programa, definição de competência e responsabilidades claras, além de apoio técnico e financeiro aos estados e municípios.
A pactuação tem como finalidade criar condições para eliminar as superposições de ações e custos administrativos, aumentar a cobertura ou elevar os valores dos benefícios. Os termos de cooperação incluem a possibilidade de cofinanciamento com ou sem complementação do benefício por parte dos governos subnacionais. Apesar de estar presente desde o início da implementação do PBF, a iniciativa não evoluiu e o quantitativo de pactuações diminui significativamente ${ }^{25}$.

A segunda modalidade pressupõe a adesão dos estados e municípios ao PBF e Cadastro Único para Programas Sociais do Governo Federal. Após a adesão, os municípios passaram a possuir responsabilidades no que tange ao cadastramento, monitoramento das condicionalidades, gestão de benefícios e oferta de programas complementares. Para os estados, a adesão implicou o compromisso de apoio aos municípios no processo de atualização cadastral e o desenvolvimento de atividades de capacitação e apoio técnico e logístico, dentre outras. Além disso, ambas as esferas

24 (Cunha e Pinto, 2008.)

25 (Cavalcante, 2009; Cunha e Pinto, 2008.)

Revista Brasileira de Monitoramento e Avaliação | Número 3 | Janeiro-Junho de 2012 
foram obrigadas a formar instâncias de controle social (ICS), compostas por integrantes do poder público e da sociedade civil. O processo, iniciado em 2005, foi bem sucedido à medida que mais de $99 \%$ dos municípios e a totalidade dos estados aderiram ao programa.

Concomitantemente a essa iniciativa, o governo federal passou a apoiar financeiramente as administrações locais com objetivo de ampliar e atualizar o cadastro das famílias. A medida, de caráter temporário, consistia no repasse de $\mathrm{R} \$$ 6,00 para cada cadastro atualizado, incluído ou complementado pelos municípios ${ }^{26}$. Tal estratégia tinha como objetivo superar os obstáculos técnicos e políticos que impediam a inserção cadastral da totalidade da estimativa de famílias pobres. Como resultado dessa iniciativa, o Ministério do Desenvolvimento Social e Combate à Fome (MDS) conseguiu a quantidade de famílias cadastradas necessárias para atingir a meta de expansão do programa em meados de 2006.

Predominava a percepção do MDS da necessidade de continuidade do apoio financeiro aos estados e, principalmente, aos municípios, de modo a criar condições políticas e técnicas para que várias competências da execução local do programa se desenvolvessem. Assim, criou-se o Índice de Gestão Descentralizada $(I G D)^{27}$ em abril de 2006, um indicador de qualidade de gestão que, em termos gerais, avalia o desempenho local com foco nas atividades do Cadastro Único e de acompanhamento das condicionalidades do programa. A partir desse índice, que varia de 0 a $1^{28}$, multiplica-se o valor de referência de $\mathrm{R} \$ 2,50$ por família beneficiária no município para fins do repasse financeiro mensal. Caso o município tenha um índice inferior a 0,55 não ocorrem repasses às prefeituras no mês de referência, sem prejudicar os benefícios às famílias.

Desde quando começou a ser calculado, de acordo com dados disponibilizados pelo MDS, a média do índice dos municípios tem aumentado. Em abril de 2006, o IGD médio nacional era de 0,68 , enquanto em dezembro de 2008 a média subiu para 0,7529. Entretanto, os dados também demonstram disparidade no desempenho dos municípios. Em dezembro de 2008, ano de referência do IGD nesta pesquisa, por exemplo, coexistiam prefeituras com índices de 0,30 e outras que se aproximam do teto, com 0,98. Tais diferenças são persistentes, ou seja, acompanham a evolução desse indicador desde a sua criação.

Com bases nesses dados, observa-se que a grande maioria dos municípios executa as atividades do PBF e vem apresentando meLhorias. Entretanto, não é possível esclarecer as razões da variação do índice entre os mu- 
nicípios. O governo federal formulou uma estrutura de incentivos homogênea para todos os municípios brasileiros, de acordo com as orientações da literatura de descentralização ${ }^{30}$, que explica parte do desempenho municipal, mas não explica tudo. O que, portanto, influencia o comportamento dos gestores municipais do PBF? Em outras palavras, por que algumas prefeituras são bem-sucedidas na gestão das condicionalidades e do Cadastro Único enquanto outras não são?

A análise dos determinantes da gestão local é um tema pouco abordado pela literatura nacional e internacional ${ }^{31}$, todavia, ela ganha importância no Brasil devido à estrutura tripartite do federalismo brasileiro. Em outras palavras, embora praticamente todos tenham aderido formalmente ao PBF, a autonomia municipal impede que os prefeitos sejam responsabilizados pela gestão de baixa qualidade desse programa.
A compreensão do comportamento dos atores envolve análise de ação coletiva, avançando para além da ótica econômica e administrativa, incluindo a dimensão político-eleitoral. Logo, pressupõe que o desempenho da execução local do PBF é ao mesmo tempo motivado e constrangido por fatores estruturais das municipalidades, como também por um conjunto de regras do jogo político e de resultados eleitorais ${ }^{32}$.

A análise dos fatores que influenciam o desempenho dos gestores, e, consequentemente, condicionam a qualidade da execução local do PBF, remete-nos à análise de múltiplas dimensões simultaneamente. Portanto, é importante responder à seguinte questão: quais os efeitos de fatores de natureza político-eleitoral, como competição eleitoral, alinhamento partidário-ideológico e participação política, e de aspectos econômicos e financeiros sobre a gestão descentralizada do PBF?

\footnotetext{
26 Criado pela Portaria GM/MDS n 360 de 12 de julho de 2005. Tal norma foi alterada pela Portaria GM/MDS n 754 de 2010 e pela Portaria GM/MDS nº 319 de 2011.

27 Criado pela Portaria GM/MDS n 148 de 27 de abril de 2006 e regulamentado pela Lei nº 12.058, de 13 de outubro de 2009. A Portaria supracitada foi alterada pelas Portaria GM/MDS nº 754 de 2010 e Portaria GM/MDS nº 319 de 2011.

28 Embora não seja objeto dessa pesquisa, os estados também recebem recursos do IGD, entretanto, não é atrelado ao desempenho das condicionalidades e das atividades de cadastramento. As parcelas aos estados são mensais e fixas, levando em consideração o número de famílias pobres de cada localidade e um plano de ação que contemple, principalmente, ações de capacitação, apoio técnico e logístico aos municípios e emissão de documentação.
}

29 (MDS, 2008.)

30 (Kaufman e Nelson, 2004; Faguet, 1997, Arretche, 2000, 2004.)

31 (Arretche, 2002; Bossert, 1996.)

32 (North, 1990; Ostrom, 1999.)

Revista Brasileira de Monitoramento e Avaliação | Número 3 | Janeiro-Junho de 2012 


\section{Determinantes do Desempenho Municipal}

A variável a ser explicada ou dependente é o desempenho da gestão municipal no PBF representada pelo IGD, uma variável quantitativa contínua que oscila entre 0 e 1 , detalhada no Anexo. Quanto maior o valor do indicador, meIhor o acompanhamento das condicionalidades e a qualidade das atividades de cadastramento das famílias pela prefeitura. Os valores utilizados pela pesquisa referem-se ao cálculo do índice em dezembro de 2008, ou seja, passados mais de dois anos e meio da criação do IGD.

Quanto às variáveis explicativas ou independentes, elas são separadas em dois grandes grupos: político-eleitoral e administrativo/financeira, além das variáveis de controle.

A primeira dimensão visa testar se fatores da dinâmica política municipal influenciam as decisões dos gestores municipais. A expectativa é de que essas variáveis apresentem coeficientes estatisticamente significativos e positivos.

O pressuposto teórico é de que a adesão, o empenho e o comprometimento do gestor local também estariam diretamente relacionados às suas escolhas racionais e estratégicas visando, em última instância, à sobrevivência política ${ }^{33}$. Essas escolhas, por sua vez, são condicionadas, em grande parte, aos estímulos a que eles estão sujeitos. No contexto de descentralização, a transferência de responsabilidades muda os incentivos e constrangimentos dos atores políticos locais à medida que eles passam a ter suas ações relativas à determinada política pública avaliadas pelos seus eleitores.
Uma série de pesquisas vem demonstrando que a competição eleitoral, isto é, o quanto as disputas por cargos públicos são acirradas, é uma das principais causas de resultados políticos positivos, que incluem, por exemplo, meLhoria na política de direitos humanos ${ }^{34}$, na paz doméstica e internacional ${ }^{35}$ e na gestão municipal de saneamento ${ }^{36}$. Nesse sentido, esta é uma ferramenta para a geração de accountability, embora não seja o único instrumento democrático ${ }^{37}$. Espera-se que a Competição Eleitoral38 atue como estímulo e controle democrático para que os políticos desempenhem melhor as atividades locais do PBF.

No que tange à ideologia ou ao alinhamento partidário, a finalidade é investigar se as diferenças políticas facilitam ou atrapalham a cooperação em torno da implementação da política pública, conforme estudos indicam ${ }^{39}$. Embora os repasses de IGD sejam compulsórios de acordo com critérios impessoais, a variável prefeito de Partido de Oposição ${ }^{40}$ tem como finalidade verificar se o alinhamento partidário tem reflexos na predisposição dos políticos locais para investir num programa do governo federal que é administrado por um partido da fora da base de sustentação política.

Quanto à proximidade ideológica, em função da histórica identificação dessa corrente com o combate à pobreza e à desigualdade social no Brasil, a expectativa é de que governos de Partidos de Esquerda ${ }^{41}$ possuam um desempenho mais positivo em relação aos demais.

Apesar da obrigatoriedade do voto no Brasil, é possível mensurar Participação Eleitoral Efetiva ${ }^{42}$, à medida que existem as opções ao 
cidadão de votar branco e nulo. Além disso, as penalidades relativas ao não comparecimento eleitoral são brandas, o que tem reflexo nas taxas de abstenção.

\section{Estudos recentes vêm procurando explicar a importância do PBF na composição do elei- torado de Lula, por exemplo, Licio, Rennó e Castro (2009) comprovam, com base numa amostra probabilística nacional, correlações}

entre os beneficiários do PBF e o voto no Lula, bem como efeitos nas avaliações positivas do seu governo. A partir dessa associação entre beneficiários do programa e o apoio a Lula, a última variável de natureza política - Votação no Lula ${ }^{43}$ nas eleições de 2006 - tem como finalidade investigar se a preferência ideológica do eleitorado exerce efeitos sobre o empenho dos prefeitos na melhoria da execução do programa.

33 (Ostrom, 1999.)

34 (Beer e Mitchell, 2004.)

35 (Bueno de Mesquita et al, 1999.)

36 (Cleary, 2007.)

37 É claro que na prática muitas vezes esses mecanismos apresentam problemas, por exemplo, os eleitores carecem de informações para fazerem julgamentos sobre os candidatos e a existência de diversas dimensões de avaliação do desempenho do gestor que podem minar essa conexão eleitoral ideal.

38 Existem diversas formas de se calcular a competição eleitoral, como o efetivo número de partidos ou sofisticados cálculos da diferença entre o vencedor e os demais concorrentes (Cleary, 2007), todavia, em função da multiplicidade do sistema partidário brasileiro, optou-se por um cálculo que mesmo mais simples consegue retratar a competitividade do sistema político municipal. Dessa forma, a Competição Eleitoral é uma variável dicotômica elaborada com base nos pleitos municipais (1996, 2000 e 2004),em que se estabelece valor de 1 quando ao menos em duas ocasiões das três eleições supracitadas um candidato vence a eleição municipal com menos de $45 \%$ dos votos válidos e valor de 0 na situação oposta. Os municípios que tiveram segundo turno ao menos duas vezes também assumem o valor de 1 (Coelho, 2009).

39 (Cox e McCubbins, 1986; Arretche e Rodden, 2004.)

40 Partido de Oposição é uma variável dicotômica na qual é atribuído o valor de 1 caso o prefeito seja da oposição ao governo federal e 0 para prefeito da base governista. Os dados referem-se aos partidos que compõem a base aliada do governo federal no ano de 2006.

41 Prefeito de Partido de Esquerda é uma variável dicotômica na qual é atribuído o valor de 1 para caso afirmativo e 0 para o oposto. Os dados referem-se aos partidos do prefeito no ano de 2006 que se autodeclaram de esquerda.

42 A Participação Eleitoral Efetiva corresponde à razão entre o número total de votos válidos no município menos os votos brancos/nulos e o total de eleitores cadastrados para votar. A variável é resultante da média aritmética das eleições para prefeito de 1996,2000 e 2004.

43 A variável consiste no percentual de votos válidos para o candidato do PT, Luís Inácio Lula da Silva, no segundo turno das eleições de 2006.

Revista Brasileira de Monitoramento e Avaliação | Número 3 | Janeiro-Junho de 2012 
Além desses fatores de ordem política, é notória a perspectiva de que restrições nas condições financeiras que têm reflexos na capacidade operacional são obstáculos para o desempenho municipal dos programas governamentais no Brasil44. De acordo com Abrúcio (2006), o problema é ainda agravado em função da insuficiência arrecadatória de muitas municipalidades, particularmente dos pequenos municípios que representam a grande maioria. Uma opção para se analisar a questão é a Dependência Financeira do Município em relação às Transferências Constitucionais ${ }^{45}$. Em outras palavras, quanto maior a participação das transferências, proporcionalmente, na arrecadação municipal, o indicador mostra o quanto a capacidade de arrecadação da prefeitura é pequena, e, consequentemente, aponta para a dificuldade dessas em arcar com custos extras e investir nas atividades de gestão do PBF. Entretanto, essa relação é bastante influenciada pelo tamanho do município. Por isso, procurou-se classificar a proporção de transferências relativas às receitas segundo a sua distribuição nos quartis (abaixo do $1^{\circ}$ quartil, entre a mediana e $3^{\circ}$ quartil) dentro de cada porte de municípios como: muito baixa, baixa, média e alta. Isso porque os municípios podem ter a dependência alta se comparada entre municípios de portes diferentes, mas relativamente aos seus semelhantes, não.

Considerando a diversidade demográfica e de fatores socioeconômicos do Brasil e seus consequentes reflexos sobre a capacidade de atuação das prefeituras, serão utilizadas como variáveis de controle: População, Distância da Capital, uma variável de Anos de Estudo da População, percentual de Cobertura do PBF no município, além da variável dummy, município das regiões Norte e Nordeste, que procura verificar se o fato de o município pertencer a essas regiões, historicamente menos desenvolvidas, tem influência sobre as variáveis dependentes da pesquisa. Por fim, estudos pioneiros sobre o IGD afirmam que quanto mais pobre o município, melhor 0 índice de gestão ${ }^{46}$. 0 argumento subjacente é que a pobreza da população do município reflete na demanda por melhorias dos serviços que, em última instância, impactaria na qualidade da execução do programa. Assim, para capturar aspectos relacionados ao trabalho e renda utilizaremos a variável Situação Econômica do Município ${ }^{47}$ para as duas políticas.

\section{Metodologia}

A pesquisa utilizará o método de regressão múltipla, que é uma técnica estatística que busca explicar uma variável por meio da relação linear dela com outras variáveis, denominadas de explicativas, preditoras ou independentes, a partir de valores fixos conhecidos ${ }^{48}$. A despeito das suas limitações quanto ao estabelecimento de inferências causais, a regressão múltipla tem como grande virtude a capacidade de espelhar, com alta fidedignidade, a complexidade de relacionamentos que caracterizam as ciências sociais e comportamentais ${ }^{49}$.

O objetivo do trabalho é explicar o desempenho captado pelo IGD por meio do modelo estatístico com múltiplas variáveis, para testar a hipótese sobre a relação entre as variáveis explicativas propostas na seção anterior, verificando se essas variáveis exercem algum efeito sobre a variável resposta (IGD) para melhor compreensão do resultado da política de indução à participação. 
Essa verificação é feita ao testarmos a hipótese nula a seguir:

$$
\begin{aligned}
& H_{o}: \beta_{i}=0 \\
& H_{I}: \beta_{i} \neq 0
\end{aligned}
$$

Para o seguinte modelo de regressão múltiplo:

$$
y=a+\beta_{i} X+\varepsilon
$$

Onde,

y: é a variável resposta/explicada, o IGD municipal do ano de 2008;

$\alpha$ : é o parâmetro a ser estimado que representa o intercepto;

Bi: é o vetor de parâmetros que mensuram os efeitos relativos às variáveis explicativas da matriz $X$, com todas as variáveis explicativas da seção 4;
$X:$ é a matriz de variáveis explicativas/ independentes com todas as variáveis;

$\varepsilon$ : é o vetor dos erros, supondo que os erros têm distribuição Normal com média igual a zero e variância $\sigma^{2}$ l.

O método de estimação a ser utilizado é o método dos mínimos quadrados ordinários que, em síntese, minimiza a soma dos quadrados dos resíduos da regressão de modo a maximizar o grau de ajuste do modelo. 0 objetivo principal é estimar os parâmetros, ou seja, o intercepto e os valores dos coeficientes de regressão ( $\beta$ ) para as variáveis independentes.

Tais estimativas visam observar a existência dos efeitos que cada variável independente pode exercer sobre a variável explicada, bem como a sua intensidade e direção (se positiva ou negativa).

44 (Almeida, 1996; Affonso; Silva, 1996; Arretche, 2000.)

450 indicador é referente ao exercício financeiro de 2005. Os dados são oriundos do Suplemento Especial da Assistência Social do MUNIC/IBGE 2005 e da Secretaria de Tesouro Nacional do Ministério da Fazenda.

46 (Estrella e Ribeiro, 2008; Monteiro et al 2008; Cunha e Pinto, 2008.)

47 indicador refere-se Índice FIRJAN de Desenvolvimento Municipal (IFDM) na área de Trabalho e Renda de 2006. Ele é composto por um conjunto de doze variáveis que mensuram as dimensões de emprego formal e salário médio da população e varia de 0 a 1. Quanto mais próximo de 1, melhor a situação econômica do município. 0 IFDM tem recorte municipal e abrangência nacional e mensura três principais áreas de desenvolvimento humano: emprego e renda, educação e saúde. A principal vantagem da utilização desse índice deve-se a sua periodicidade anual.

48 (Tabachnick e Fidell, 1996; Cohen e Cohen, 1975.)

49 (Cohen e Cohen, 1975.)

Revista Brasileira de Monitoramento e Avaliação | Número 3 | Janeiro-Junho de 2012 
TABELA 3: RESULTADOS DO MODELO DA PESOUISA

\begin{tabular}{|c|c|c|}
\hline VARIÁVEL & $\begin{array}{l}\text { ESTIMATIVA } \\
\text { DO PARAMÊTRO (EFEITO) }\end{array}$ & P-VALOR \\
\hline Intercepo & 0,47 & $0,00 * * *$ \\
\hline Anos de Estudo da População & 0,00 & 0,71 \\
\hline Cobertura do Programa Bolsa Família & 0,11 & $0,00 * * *$ \\
\hline Competição Eleitoral & 0,00 & 0,34 \\
\hline Situação Econômica do Município & $-0,05$ & $0,00 * * *$ \\
\hline Distância em Km da Capital & 0,00 & 0,21 \\
\hline Participação Eleitoral Efetiva & 0,16 & $0,00 * * *$ \\
\hline População do Município & 0,00 & $0,00 * * *$ \\
\hline Votação no Lula & 0,07 & $0,00 * * *$ \\
\hline Dependência Financeira do Muinicípio & 0,00 & 0,51 \\
\hline Partidos de Esquerda & 0,00 & 0,12 \\
\hline Partidos de Oposição & 0,00 & 0,89 \\
\hline Pertencer às Regiões Norte e Nordeste & 0,02 & $0,00 * \cdots$ \\
\hline
\end{tabular}

Nivel de significância estatística: $* * *=1 \%, * *=5 \%, *=10 \%$. Número de observações=5.561.

O universo dessa investigação é quase a totalidade das cidades brasileiras ${ }^{50}$, com um número amplo de observações disponíveis. As bases de dados utilizadas são oriundas de instituições oficiais de governo e, portanto, acredita-se que são mais confiáveis, o que diminui as chances de erros das predições.

\section{Resultados da Pesquisa}

A tabela 3 a seguir apresenta os coeficientes de regressão de cada uma das variáveis, bem como suas respectivas estatísticas de teste (p-valor).

Observa-se assim que a metade das variáveis independentes não possui significância estatística. Nas variáveis de ordem político-eleitoral, fatores como competição eleitoral, alinhamento partidário e ideologia não apresentam efeitos perceptíveis na qualidade da execução municipal do PBF. Tais resultados sugerem que a propensão dos gestores locais a investir nas atividades do programa não sofre influência da intensidade da disputa eleitoral, da proximidade partidária com a base de sustentação do governo federal e da posição ideológica do prefeito. Nessas últimas, o resultado desmistifica o senso comum do campo de estudo no Brasil que defende que partidos aliados e/ou de esquerda tendem a ser mais envolvidos com a gestão da política social. Por outro lado, o grau de participação eleitoral no município e o percentual de votação no Presidente Lula demonstram relação com o IGD. O primeiro indica que o aumento do índice impacta em 0,16 da variação da participação eleitoral municipal e o apoio maior a Lula em 0,07. Essas correlações dão indicações de que a população mais participativa e que apoia um político bastante identificado com a política social no município influenciam a qualidade da implementação desse tipo de política. 
As variáveis Distância da Capital do Estado, Anos de Estudo e Dependência Financeira também não apresentaram significância estatística. A primeira, de caráter espacial, indica um resultado positivo da estratégia de descentralização do programa, uma vez que o bom desempenho no IGD não ficou restrito às capitais ou cidades próximas. Já a variável financeira é interessante à medida que se esperava que as restrições orçamentárias do município fossem um fator que prejudicasse o desempenho das atividades locais do PBF.

Em relação à variável demográfica População do Município, esta apresenta uma relação negativa com o IGD, isto é, quanto maior o número dos habitantes da cidade, pior a execução local do PBF. No sentido oposto, a cobertura do PBF possui uma relação positiva, isto é, o IGD aumenta em 0,11 para cada unidade de aumento na cobertura.

Finalmente, as variáveis Situação Financeira do Município e Pertencentes às regiões Norte e Nordeste são significativas, embora também com relações opostas. A primeira é negativa e corrobora o argumento de que quanto mais pobre o município, mais pressão pela qualidade da execução do programa. E a variável regional apresenta uma relação positiva, isto é, municípios do Norte e Nordeste tendem a possuir um desempenho melhor na execução do PBF. Este último contrapõe a percepção comum de que os municípios dessas regiões possuem pior gestão das políticas públicas. Todavia, esses dois resultados também po- dem indicar que prefeituras de cidades mais pobres apresentam melhores desempenhos no PBF justamente por necessitarem de mais recursos e, assim, o IGD tem mais importância para estes do que para administrações locais mais ricas.

\section{Considerações Finais}

O presente artigo procurou contribuir para a compreensão das políticas sociais no Brasil tendo como objeto de estudo a implementação de um programa governamental de grande relevância e que se encontra distribuído em todo território brasileiro. Para tanto, a análise focou nos determinantes da gestão municipal dentro do debate de descentralização da política pública brasileira.

Essa análise é fundamental, uma vez que a maioria dos estudos sobre descentralização carece de fundamentação de natureza positiva, como, por exemplo, a dificuldade dos analistas em apresentar inferências consistentes acerca do relacionamento causal entre descentralização e muitos dos seus benefícios propagados. Tais limitações, por sua vez, implicam fragilidade nas análises e impedem a elaboração de proposições normativas válidas.

Diante do desafio de abordar o tema sob uma perspectiva positiva, foram selecionadas variáveis que representam boa parte das questões sobre as razões que influenciam o comportamento da gestão municipal, bem como um número de observações bastante amplo,

50 Brasília foi excluída da análise por não ser um município e Fernando de Noronha por não possuir eleições.

Revista Brasileira de Monitoramento e Avaliação | Número 3 | Janeiro-Junho de 2012 
o que amplia a capacidade de generalização. Porém, apesar de terem sido incluídas doze variáveis, as limitações na disponibilidade de informações municipais impediram uma análise ainda mais sofisticada e compreensiva.

Não obstante, alguns resultados suscitam discussões relevantes. Primeiro, a estratégia do IGD não foi bem-sucedida apenas por atingir todos os municípios brasileiros, mas principalmente pelo fato de ter criado incentivos às prefeituras para desempenharem bem as atividades do PBF independentemente da sua posição geográfica ou da situação econômica. Ademais, no que tange à dimensão política, embora a variável Participação Política apresente relação positiva com o desempenho municipal no PBF, os resultados da maioria das variáveis ajudam a contrapor argumentos de que os políticos locais são pressionados pelo grau de competição eleitoral ou por proximidade ideológica e partidária na gestão das políticas sociais. Tais descobertas são interessantes à medida que reduzem a importância da questão política, muitas vezes artificialmente superdimensionadas pela opinião pública.

\section{Anexo - Índice de Gestão Descentralizada}

O IGD é um indicador que, em termos gerais, avalia o desempenho da execução local do PBF, variando entre 0 a 1 . 0 índice ${ }^{51}$ foi alterado, entretanto, como os dados deste artigo se referem ao exercício de 2008, este Anexo detalha a metodologia de cálculo vigente no referido ano. O IGD é composto pela média aritmética das seguintes variáveis:

I) Taxa de cobertura de cadastros;

II) Taxa de atualização de cadastros;

III) Taxa de crianças com informações de frequência escolar e;

IV) Taxa de famílias com acompanhamento das condicionalidades de saúde.

O índice do cadastro é a média dos valores das duas primeiras taxas. A taxa de cobertura de cadastros indica a quantidade de famílias com cadastro válido em relação à estimativa de famílias do município com renda familiar 
mensal per capita de até meio salário mínimo, ou seja, reflete a capacidade da gestão municipal de identificar e cadastrar as informações destas famílias. Já a segunda taxa indica a quantidade de famílias que tiveram seus dados cadastrais atualizados nos 24 meses anteriores à última atualização ou inclusão da família no Cadúnico em relação à estimativa de famílias de baixa renda do município, refletindo, assim, a postura da prefeitura em manter atualizado a base de dados do progra$m a^{52}$.

No que tange às condicionalidades da educação, os valores refletem a taxa de crianças com informações de frequência escolar, isto é, a quantidade de crianças e adolescentes com informações acompanhadas pelo Sistema de Frequência Escolar do MEC em relação ao total de crianças e adolescentes pertencentes a famílias beneficiárias do PBF no município. A taxa de famílias com acompanhamento das condicionalidades de saúde indica a quantidade de famílias com registro de informações no Sistema de Vigilância Alimentar e Nutricional (SISVAN) em relação ao total de famílias beneficiárias do PBF nesse perfil de condicionalidades ${ }^{53}$. Nestes casos, os indicadores retratam a capacidade da execução local em monitorar o atendimento de tais serviços públicos de forma articulada com as respectivas secretarias responsáveis.

Cabe salientar que esses índices possuem limitações, seja na sua operacionalização ou na abrangência, mas não desqualificam o índice do PBF, haja vista sua capacidade de mensuração de efetividade de ações essenciais ao programa. A metodologia mede com relativa confiança a atuação do governo municipal na identificação, seleção e cadastramento das famílias, como também no acompanhamento de um conjunto extenso de beneficiários nas ações relativas às condicionalidades de saúde e educação. Ademais, o índice exerce funções de monitoramento e controle social da gestão do programa, pois tais atividades são mensuradas de forma simples, transparentes e com regularidade mensal.

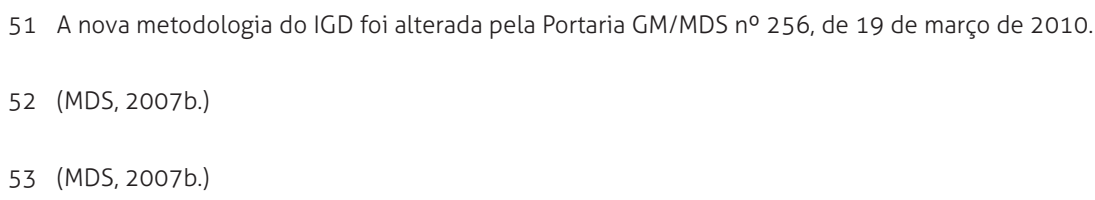

Revista Brasileira de Monitoramento e Avaliação | Número 3 | Janeiro-Junho de 2012 
ABRUCIO, Fernando. A coordenação federativa no Brasil: a experiência do período $\mathrm{FHC}$ e os desafios do governo Lula. Revista de Sociologia e Política, Curitiba, n. 24, pp. 41-67, 2005.

Para além da descentralização: os desafios da coordenação federativa no Brasil. In: FLEURY, Sônia (Org.). Democracia, Descentralização e Desenvolvimento: Brasil e Espanha. 1 ed. Rio de Janeiro: FGV Editora, pp. 77-125, 2006.

AFFONSO, Rui; SILVA, Pedro (Orgs). Descentralização e políticas sociais. São Paulo: FUNDAP, 1996.

ALMEIDA, Maria Hermínia Tavares. Federalismo e Políticas Sociais. In: AFFONSO, Rui; SILVA, Pedro (Orgs). Descentralização e Políticas Sociais. São Paulo: FUNDAP, 1996.

Recentralização a Federação? Revis-

ta de Sociologia Política, n. 24, pp. 29-40, junho de 2005.

ARRETCHE, Marta. Estado federativo e políticas sociais: determinantes da descentralização. São Paulo: FAPESP, 2000.

Relações Federativas nas Políticas

Sociais. Educ. Soc. Campinas, v. 23, n. 80, pp. 2548, setembro de 2002.

Federalism and Place-Equality Policies: a case study of policy design and outputs. EUI Working Papers. SPS 2, 2009.

RODDEN, Jonathan. Política Distributiva na Federação: Estratégias Eleitorais, Barganhas Legislativas e Coalizões de Governo. DADOS - Revista de Ciências Sociais. Rio de Janeiro: Vol. 47, n. 3, pp. 549-576, 2004.

BEER, Caroline; MITCHELL, Neil. Democracya and Human Rights in the Mexican States: Elections or Social Capital? International Studies Quarterly, v.4, n.8, p. 93- 312, jun. 2004.

BOSSERT, Thomas. Decentralization. In: JANOVSKY, $K$ (ed.). Health policy and systems development an agenda for research. Geneva: World Health Organization, pp. 147-60, 1996.
BRASIL. Ministério do Desenvolvimento Social e Combate à Fome. Análise da Pesquisa sobre a Gestão Descentralizada do Programa Bolsa Família. Junho, 2007a.

Financiamento da Assistência Social no Brasil. Caderno SUAS, v. 2, n. 2, Brasília: MDS, 2007b.

A Evolução dos Recursos dos Programas de Transferência de Renda. Caderno SUAS, v. 3, n. 3, Brasília: 2008.

CAVALCANTE, Pedro. Programa Bolsa Família: descentralização, centralização ou gestão em redes? Revista do Serviço Público, v.. 60, n. 1, jan/mar, 2009.

CHEEMA, G. Shabbir; RONDINELLI, Dennis (Eds.). Decentralization and Development: Policy Implementation in Developing Countries. Beverly Hills: Sage Publications, 1983.

Decentralizing Governance: Emerging Concepts and Practices. Washington, DC: Brookings Institution Press, 2007.

CLEARY, Matthew R. Electoral Competition, Participation, and Government Responsiveness in Mexico. American Journal of Political Science, v.. 51, n. 2, pp. 283-299, 2007.

COELHO, Denílson. Teorias de difusão de políticas sociais e a natureza da competição política. Apresentado no Seminário Desenvolvimento e Desigualdade no Sul Global. Providence: Summer Brown Institute, maio-junho, 2009.

COHEN, Jacob; COHEN, Patricia. Applied multiple regression/correlation analysis for the behavioral sciences. Hillsdale: Lawrence Erlbaum Associates, 1975 .

COHN, Amélia; FONSECA, Ana. O Bolsa-Família e a questão social. Revista Teoria e Debat,. n. 57, março/abril, 2004.

COK, Gary; MCCUBBINS, Matthew. Electoral Politics as a Redistributive Game. Journal of Politics, v.. 48, pp. 370-389, 1986. 
CUNHA, Rosani ; PINTO, Bruno. O Programa Bolsa Família como estratégia para redução da pobreza e da desigualdade no Brasil e os processos de cooperação e coordenação intergovernamental na sua implementação. In:Congreso Internacional del CLAD sobre la Reforma del Estado y de la Administración Pública, 13. Buenos Aires, 2008.

DELGADO, Guilherme; JACCOUD, Luciana; NOGUEIRA, Roberto. Seguridade Social: redefinindo o alcance da cidadania. In: IPEA. Políticas Sociais: acompanhamento e análise, Vinte Anos da Constituição Federal. Brasília: IPEA, 2008.

ESTRELLA Juliana; RIBEIRO, Leandro. Qualidade da gestão das condicionalidades do programa Bolsa Família: uma discussão sobre o Índice de Gestão Descentralizada. Revista de Administração Pública. FGV; v. 42, n.3, pp. 625-641, 2008.

FAGUET, Jean-Paul. Decentralization and Local Government Performance. Technical Consultation on Decentralization, Rome: FAO, 1997.

KAUFMAN, Robert; NELSON, Joan M. Crucial needs, weak incentives: social sector reform, democratization, and globalization in Latin America. Washington: Wilson Center Press, 2004.

LICIO, Elaine; RENNO, Lúcio; CASTRO, Henrique. Bolsa Família e voto na eleição presidencial de 2006: em busca do elo perdido. Opinião Publica, v. 15, n.1, pp. 31-54, 2009.

LINDERT, Kathy et al.. The Nuts and Bolts of Brazil's Bolsa Família Program:Implementing Conditional Cash Transfers in a Decentralized Context. . Washington, DC: World Bank, 2007. (Social Protection Discussion Paper No 709).

MEDEIROS, Marcelo; BRITTO, Tatiana; SOARES, Fabio Veras. Targeted Cash Transfer Programmes in Brazil: BPC and the Bolsa Família. Brasilia: International Policy Centre for Inclusive Growth, 2008. (IPC-IG Working Paper 46).
MELO, Marcus André. Federalismo e Política Social: as Vicissitudes da Descentralização. In: MELO, Norma L.;LEAL, Suely M. R. (Orgs). Relação Público-Privado: do Local ao Global. Recife: UDUFPE, 1996.

MONTEIRO, Doraliza; FERREIRA, Marco Aurélio; DENÚBILA, Laís. Alocação de Recursos e Eficiência na Gestão do Programa Bolsa Família em Minas Gerais. Revista de Ciências Humanas, v.. 8, n. 2, pp. 193-207, jul/dez, 2008.

NELSON, Joan M. The Politics of Health Sector Reform: Cross-National Comparisons. In: KAUFMAN, Robert; NELSON, Joan M (Eds.). Crucial needs, weak incentives: social sector reform, democratization, and globalization in Latin America. Washington: Wilson Center Press, cap. 2, 2004.

NORTH, Douglas. Institutions, Institutional Change, and Economic Performance. New York: Cambridge University Press, 1990.

OSTROM, Elinor. Institutional Rational Choice: An Assessment of the IAD Framework. In: SABATIER, Paul (Ed.). Theories of the Policy Process. Boulder, CO: Westview Press, 1999.

SOARES, Fabio Veras; RIBAS, Rafael Perez; OSÓRIO, Rafael Guerreiro. Avaliando o Impacto do Programa Bolsa Família: uma comparação com programas de transferência condicionada de renda de outros países. . International Policy Centre for Inclusive Growth, 2007. (IPC evaluation note, n. 1).

SOARES, Sergei Suarez; OSÓRIO, Rafael Guerreiro; SOARES, Fabio Veras; MEDEIROS, Marcelo; ZEPEDA, Eduardo. Conditional Cash Transfers in Brazil, Chile and Mexico: Impacts upon Inequality. International Policy Centre for Inclusive Growth, 2007. (Working Papers 35).

TABACHNICK, Barbara; Fidell, Linda. Using multivariate statistics. 3. ed., New York: Harper Collins, 1996.

WORLD BANK. Decentralization: What, Why and Where. Disponível em: <http://www1.worldbank. org/publicsector/decentralization/what.htm>. Acesso em: 25 de março de 2010.

Revista Brasileira de Monitoramento e Avaliação | Número 3 | Janeiro-Junho de 2012 